\title{
Glauber e o barroco: cinema da
} resistência e contraconquista

\author{
Pedro Vaz Perez ${ }^{1}$
}

1 Jornalista e mestrando do Programa de Pós-Graduação em Comunicação Social da Pontifícia Universidade Católica de Minas Gerais (PUC Minas) Bolsista da Fapemig. pedrovazperez@gmail.com 


\section{Resumo}

À luz da proposta de um barroco americano de contraconquista, sugerida por Lezama Lima, o presente estudo busca identificar a expressão desse barroco no filme Deus e o diabo na terra do sol, de Glauber Rocha. Tendo em vista as relações dialéticas da colonização portuguesa no Brasil e seus resquícios, bem como a reincidência de mitos culturais em diferentes momentos históricos, este artigo buscará compreender como o cineasta inscreve uma visão de mundo, realizando um possível cinema de contraconquista. Por fim, será realizada uma aproximação entre Glauber e os modernistas brasileiros, que, ao revisitarem o acervo barroco colonial, identificaram gestos de tensão com relação aos modelos artísticos miméticos europeus. Longe de uma interpretação histórica e anacrônica do acervo, buscaram fazer uso do que viram para seu próprio projeto artístico.

\section{Palavras-chave}

Glauber Rocha, cinema, barroco, colonização, modernismo brasileiro.

\section{Abstract}

Regarding Lezama Lima's concept of a counter-conquest American baroque, the following article intends to identify its expression in the movie Deus e o diabo na terra do sol (a.k.a. Black god, white devil), from Glauber Rocha. Owing to dialectic relationships earned from Brazilian's Portuguese colonization and its remnants, and to the relapse of cultural myths on different historical periods, this study will seek to understand how the film-maker inscribes a world-view, realizing a potential counter-conquest cinema. Lastly, shall be made an approach between Glauber and the Brazilian modernists, who, while revisiting the colonial baroque collection, have identified tension gestures in relation to European mimetic art model. Far from producing a historical and anachronistic interpretation, they have sought to make use of what they have seen for their own art project.

\section{Keywords}

Glauber Rocha, cinema, baroque, colonization, Brazilian modernism. 
"Jamais fomos cathechisados. Fizemos foi Carnaval".

Manifesto Antropófago, de Oswald Andrade

\section{Colonização e barroco americano}

O barroco, nas especificidades com as quais foi absorvido pela América, tal como exposto por Bragança (2008) em análise do filme Barroco, de Paul Leduc, é tido como instrumento de expressão e resistência da contraconquista do colonizado, para muito além da contrarreforma católica. Para o autor, a busca por alteridades e modelos identitários na América fez emergir um "entrelugar" que pôs sob suspeita dualidades rígidas, tais como margem/centro, metrópole/ colônia, europeu/indígena, destruindo conceitos de unidade e pureza em uma tradição da ruptura, em permanente tensão entre a presença do olhar do colonizador e as mais diversas expressões de resistência e desconstrução desse olhar, relações de poder "inscritas desde o projeto expansionista ibérico do século XVI" (BRAGANÇA, 2008, p. 163). Um "entre-discurso da periferia" que retorna ao centro imagens sobre si mesmo que o centro nunca poderá produzir. Dessa forma, o barroco americano, para muito além do estilo, é um devir, e sua expressão não está associada a um período histórico determinado, mas pode se fazer ativamente presente em diferentes momentos históricos, por meio de seus operadores. O conceito de barroco trabalhado por Bragança é emprestado da obra do cubano José Lezama Lima, A expressão americana (1988), originalmente publicada em 1957. Em movimento semelhante, à luz da noção de um barroco de contraconquista, este artigo buscará uma aproximação ao filme Deus e o diabo na terra do Sol, de Glauber Rocha.

O termo contraconquista pressupõe a figura de um conquistador, um colonizador, mas este último não se mostra personificado ou atado a algo sólido. Como já observado, não se deve abordar a questão da colonização a partir de uma relação maniqueísta entre colônia e matriz históricas - mesmo 
que a herança colonial se faça, décadas depois, ainda bastante presente. Bosi (1992), em sua Dialética da colonização, atualiza o debate. Para ele, a formação colonial no Brasil esteve, economicamente, relacionada aos interesses de mercadores de escravos, açúcar e ouro; politicamente, ao absolutismo reinol e ao mandonismo rural, que deram origem aos estilos de vida patriarcal, entre os poderosos, e escravista ou dependente, entre os subalternos. Apesar do processo expansionista dos anos 70 e 80, essa dominação ainda se fazia presente quando da publicação da obra de Bosi, em 1992, entretanto, com outra face: "foi e continua sendo uma reatualização em nada menos cruenta do que foram as incursões militares e econômicas dos tempos coloniais" (BOSI, 1992, p. 23)². A problemática da colonização e de seus resquícios também é complexificada em diversos momentos da obra de Glauber, tanto em filmes quanto em escritos. Seu manifesto Estética da fome - apresentado em 1965, durante discussões sobre o Cinema Novo em Gênova - visava demonstrar as formas paternalistas europeias em relação ao "Terceiro Mundo":

A América Latina permanece colônia e o que diferencia o colonialismo de ontem do atual é apenas a forma mais aprimorada do colonizador [...] O problema internacional da América Latina é ainda um caso de mudança de colonizadores, sendo que uma libertação possível estará ainda por muito tempo em função de uma nova dependência (ROCHA, 2004, p. 64).

Essa abordagem de Glauber se aproxima daquela exposta por Bosi. Este último demonstrou que a dominação ainda se dava de uma forma diluída, menos visível, introjetada de tal maneira no dominador, num culto involuntário da autoridade, que ele nem se apercebe dessa realidade, excluindo, em sua própria alienação, a existência concreta do dominado. Logo, historicamente, 
geral) foram colonizadas pela cultura rústica ou, eventualmente, urbana dos portugueses, e pelo catolicismo ritualizado dos jesuítas; e agora, já em plena mestiçagem e em plena sociedade de classes capitalistas, estão sendo recolonizadas pelo Estado, pela Escola Primária, pelo Exército, pela indústria cultural e por todas as agências de aculturação que saem do centro e atingem a periferia (BOSI, 1992, p. 334).

Tanto para Bosi quanto para Glauber a colonização permanece, mesmo que camuflada; mas junto a ela traz a resistência, que subsiste. Dessa forma, é proposta aqui uma aproximação entre os pensamentos dos dois autores ao de Lezama Lima. Tomando Aleijadinho como metáfora ${ }^{3}$, o autor vê o barroco como uma "lepra criadora", uma "dificuldade" americana: "somente o difícil é estimulante; somente a resistência que nos desafia é capaz de assestar, suscitar e manter nossa potência de conhecimento" (LEZAMA LIMA, 1988, p. 47). A dificuldade de que fala é a forma em devir que vai em direção à formação de um sentido, para depois buscar sua desconstrução e, enfim, atingir uma visão histórica tecida por imagens contrapontísticas. A lepra de Aleijadinho é vista como metáfora dolorosa desse devir; impureza não somente física mas também espiritual; contaminação que produz um corpo em processo de decomposição e de transformação.

[...] e do triunfo prodigioso de Aleijadinho [...] Eis aí a prova mais decisiva, quando um esforçado da forma recebe um estilo de grande tradição, e longe de diminuí-lo o devolve enriquecido, símbolo de que este país alcançou a sua forma na arte da cidade (LEZAMA LIMA, 1988, p. 105).

Ao cabo, o autor propõe ver no barroco o autêntico começo da América, por constituir uma síntese hispano-indígena e hispano-negroide - Lezama considera o mundo lusitano dentro do hispânico - , fazendo emergir um sentido revolucionário nessa estética: uma política subterrânea da contraconquista pela tensão e pelo plutonismo transculturadores dos mestiços. Às modalidades 
de um barroco europeu ele atribui: acumulação sem tensão e assimetria sem plutonismo. Tensão e plutonismo, portanto, são elementos característicos do barroco americano, sendo plutonismo um "fogo originário que rompe os fragmentos e os unifica" (LEZAMA LIMA, 1988, p. 79). Esses elementos acabaram por representar aquisições de linguagem que, para o autor, são únicas no mundo; formas de vida e de curiosidade; a diferença americana.

\section{Um cinema da resistência}

O projeto de cinema de Glauber - que se pode assumir como antropofágico ou tropical - se aproxima da argumentação lezamiano ao incorporar, por exemplo, distintos elementos, como os longos planos de Rossellini, que acompanham e registram a ação estendida na cena de forma realista, e traços das composições de planos e da montagem vertical de Eisenstein - pensamento com imagens -, para citar apenas duas óbvias referências. Longe de mimetizá-las, Glauber as mistura a características de uma certa cultura brasileira e latino-americana, formando um caldo cultural - processo de fusão, mais do que colagem, resultando uma amálgama cinematográfica. Plutonismo glauberiano que retorna à fonte imagens enriquecidas.

Deus e o diabo na terra do Sol foi lançado em 1964, pouco mais de dois séculos após Aleijadinho ter produzido seus trabalhos. Os contextos são diferentes, mas no filme a tensão também se faz notável tanto na forma quanto no enredo. Manuel, vaqueiro, homem do povo, parte da exploração à revolta, mas sempre apegado a uma instituição superior; transita, de forma errante, entre mitos - o messianismo do beato Sebastião e a violência do Cangaço. Em situação de opressão, acaba por matar o coronel Morais. Sem perspectivas, passa a seguir o beato, que, do alto do Monte Santo, tece promessas de fartura em um ambiente onde só se veem as mazelas da fome e da seca ${ }^{4}$. Aparentemente liberto do mito após a morte de Sebastião, Manuel acaba por se 
entregar a outro, com novo rosto. Entra para o bando de Corisco, o último dos cangaceiros vivos, vendo nele semelhante esperança de salvação que vira no beato. Interessante observar que Glauber propositalmente mistura, em certos momentos, as vozes do beato e de Corisco; por vezes, vê-se um, mas ouve-se a voz do outro, manipulação possível devido à não utilização de som direto - e que fortalece a ideia de um ciclo mítico.

Há de se ponderar, com Ismail Xavier (1983), que em Deus e o diabo o folclore é evocado como resistência cultural, evitando o puro elogio romântico ao popular, ao mesmo tempo que também desautoriza a redução iluminista e a visão racionalista burguesa de um "rural arcaico". Não se trata, portanto, da reconstrução fidedigna da história, e sim de uma fábula, descompromissada com a elaboração de verdades absolutas. Lezama propõe que a história emerge não pela razão, mas por um logos poético que constrói a história pela imagem, afastando-se da causalidade do historicismo em busca de analogias que revelem o devir. A imagem participa da história, e por isso todo discurso histórico é uma ficção do sujeito. Ou seja: o historicismo recai necessariamente na linguagem. Toda cultura cria uma imaginação (imago), em uma trama que empresta a imagem à história para que o fato se torne decifrável, e um entrelaçamento de culturas é que permitirá o contraponto entre elas. Daí seria possível pensar a humanidade dividida por eras correspondentes à sua potencialidade para criar imagens - eras de imagens ou imaginárias - , como uma memória que, "ao afincar-se sobre um fato muito bem guarnecido por ela, está como que à espreita para ser emparelhada com outro fato mais longínquo e desafiador" (LEZAMA LIMA, 1988, p. 60).

Em suma, Deus e o diabo trata da saga de Manuel; sua trajetória é a principal no filme, mesmo que atravessada e complexificada pelas de outros personagens. É o primeiro personagem a ser apresentado e surge, no início da saga, com ares de herói de western. Mas a queda na intensidade da música após sua aparição e seu posterior andar trôpego e pouco expressivo até o 
cavalo desconstroem a expectativa gerada. Manuel não é um herói ${ }^{5}$, e sim um homem comum, mas que resiste. Deus e o diabo é, na raiz, um filme sobre a resistência dos homens comuns, e essa palavra não remete necessariamente a uma revolução, mesmo que a possa comportar. Remete, sim, a algo ou alguém que simplesmente perdura, apesar das adversidades. Manuel resiste como os mandacarus insistentemente filmados por Glauber ao longo de toda a obra, em meio ao sertão árido e seco. A natureza - relacionar os personagens fisicamente com seu habitat, em toda a sua extensão - parece ser central para o projeto do diretor em filmar a resistência. E para isso lança mão de movimentos de câmera, panorâmicas e travellings - logo a primeira imagem, uma aérea sobre a caatinga, apresenta a imensidão e a secura desse espaço, e, não sem significado, é nessa vastidão que são inseridos os créditos dos atores e da equipe; em outros momentos, os movimentos da câmera descrevem detalhes do ambiente, como areia, rochas e espinhos, para em seguida percorrerem, com o mesmo olhar, os personagens, como que integrando um ao outro, todos fazendo parte do mesmo universo. São igualmente dignos de comentário os marcantes planos gerais ao longo de todo o filme, com destaque para alguns na fase final, após o encontro de Manuel e Corisco, quando, habilmente, o diretor chega a enquadrar seis pessoas em meio à vegetação, em profundidades diferentes, resultando em uma belíssima composição ${ }^{6}$. Aqui não mais se distinguem homens e plantas:

5 No entanto, mais à frente é apresentado Antônio das Mortes, e ele sim surge com ares de herói, como em um verdadeiro western, devido à sua postura imponente e destemida. Mas é tema discutível se suas ações ao longo da trama mantêm a visão de herói.

6 A composição de planos marcantes é uma das marcas da filmografia de Glauber, e o interesse parece vir desde Pátio: "Como duas figuras humanas - macho e fêmea -, jogadas sobre um pátio em preto e branco com vista par o mar e céu e cercado por folhagem, partimos como a câmara, utilizada como instrumento, em busca do visual mais limpo, mais depurado, e que sairia do seu estado real para o estado de poeticidade, através unicamente da solução de enquadramento, do ponto-de-vista seletivo do cineasta em busca de elementos válidos que, na sala de montagem, Ihe propusessem o problema de "criar" o organismo rítmico, o filme em seu estado de cinema enquanto cinema (Glauber Rocha; Jornal do Brasil, 29 mar. 1959, "Suplemento dominical").

Suas composições marcantes se assemelham muitas vezes a pinturas, e é possível arriscar referências aos quadros de Di Cavalcanti, amigo e homenageado. Os planos são ainda complexificados pelo movimento; por vezes, emergem em meio a uma coreografia entre câmera e personagens, ambos em movimento no set - "câmera na mão", mas de forma nem um pouco aleatória. Dib Lutfi, responsável pela câmera de Terra em Transe, afirmou em entrevista a mim que, durante as filmagens, deixava o cinto um furo mais apertado para que Glauber prendesse as mãos nele, por trás, e literalmente o dirigisse, com a câmera em funcionamento. 
homens-mandacarus ${ }^{7}$, resistentes, sofridos, vivos e totalmente integrados à natureza. A profundidade de campo é também explorada para demonstrar a vastidão do espaço e a integração nele dos personagens: penetram na infinitude proporcionada pela grande angular, sem sair de foco; caminham, num mesmo plano, pela imensidão do plano-sertão.

Em um exemplo mais concreto, vê-se que composição, decupagem e montagem também significam de forma contundente na cena do confronto entre Manuel e o coronel Morais. O plano inicial é um de conjunto num curral, onde uma cerca separa o gado dos personagens. As linhas que formam a cerca são paralelas, mas, ao enquadrá-las transversalmente, à direita, próximas à câmera, elas ocupam quase toda a verticalidade ${ }^{8}$ do plano, para convergirem no lado oposto, em um espaço mais concentrado. Na cena, o coronel ocupa a parte direita do plano (inclusive quando está fora de quadro), com Manuel à esquerda. As linhas partem do coronel e convergem sobre Manuel, representando esteticamente o jogo de opressão e revolta naquele espaço, que pode ser visto como microcosmos da organização coronelista em todo o sertão - e, por que não, no país ou na América Latina. No desenrolar da ação, Manuel avança pela profundeza do plano em direção contrária à força da opressão representada pelas linhas - uma cena com poucos cortes - , até o momento em que as linhas atingem a horizontalidade no plano: uma neutralidade de forças. $E$, em alguns instantes, Manuel cruzará o eixo da ação, passando a ocupar a face direita do plano, que antes pertencia ao opressor; o povo se impôs à opressão, mesmo que através da violência ${ }^{9}$. Os movimentos de câmera também significam: após

7 Mandacarus surgem em diversos momentos, como na cena do enterro da mãe: a câmera enquadra primeiramente a cruz - elemento recorrente em todo o filme - , para em seguida se abrir em um plano de conjunto, composto agora por cruz ao centro e abaixo, Manuel à esquerda e Rosa à direita. Ao centro, um mandacaru parece brotar da sepultura da mãe, ao mesmo tempo em que integra o plano com aqueles personagens. Já no interlúdio, um conjunto de mandacarus, mais fortes e imponentes, surge em primeiro plano. 
o segundo corte, já tendo havido a descrita neutralização das forças, vê-se um primeiro plano do coronel, que, autoritário, afirma: "Já disse, tá dito. A lei tá comigo", enquanto a câmera se desloca da direita para a esquerda, em uma panorâmica horizontal - os últimos resquícios da opressão em vias de ser neutralizada são ainda significados pelo movimento de câmera. Esse deslocamento recoloca temporariamente as linhas em perspectiva, e elas voltam a convergir sobre Manuel, que revida, com a câmera, avançando sobre o coronel (mas ainda sem embate físico), questionando: "Que lei é essa que não protege o que é meu?". A câmera o acompanha, refazendo a panorâmica e estabelecendo mais uma vez a neutralidade das forças. Em seguida, o coronel será morto pelo facão de Manuel.

Fizeram-se notáveis, portanto, as aproximações entre as ideias de Lezama Lima e a épica glauberiana. No entanto, não se propõe aqui, obviamente, que Glauber tenha incorporado à sua estética cinematográfica forma e estilo da talha de Aleijadinho. Mas, a partir da comparação, é possível ver nesse cinema um gesto de tensão na relação colônia/colonizador, assim como o que Lezama enxergou na obra do escultor. Como em um movimento de reescrita do passado, o antigo é reapropriado como inspiração por um novo projeto artístico, livre, portanto, de anacronias, menos interessado em uma interpretação do que em fazer uso dessa tensão, percebida a posteriori, com propósitos bem determinados. Arrisca-se aqui, portanto, ver a obra de Glauber como um cinema de contraconquista, devido, principalmente, a seu caráter de resistência.

\section{Os portugueses e a razão eksistente}

A presença do mito sebastianista - que tem suas origens em Portugal em Deus e o diabo não parece ser mera coincidência. Quando Glauber demonstra a crença cega na salvação divina, ele recorre "a um imaginário brasileiro mais antigo, ou mesmo inaugural, que confere a essas profecias uma ressonância ao mesmo tempo histórica e mítica" (NAGIB, 2006, p. 31). De acordo com o mito, 
D. Sebastião, rei de Portugal desaparecido em batalha em Alcácer-Quibir, no século XVI, cujo corpo nunca fora encontrado, retornaria para salvar o povo dos problemas que sucederam sua morte. Grosso modo, o Sebastianismo é a espera por um salvador. Mas faz-se necessário aprofundamento.

De acordo com padre Antônio Vieira, um sapateiro de nome Bandarra havia profetizado em trovas, após a morte de D. Sebastião, que haveria de surgir um rei português que traria a paz mundial (VIEIRA, 1951). O tema foi recorrente em seus sermões e cartas, além de aparecer em livros como $A$ esperança de Portugal e História do futuro, nos quais interpreta as trovas. Mas vai além do retorno do rei Encoberto: anuncia o surgimento do Quinto Império, o de Cristo na Terra, sucedendo assírios, persas, gregos e romanos, governado por um rei português ao longo de mil anos. Em Sermão dos bons anos (1959), Vieira afirma que o então rei D. João IV estaria dando continuidade ao rei morto e ausente, D. Sebastião, cumprindo a promessa que teria sido feita por Deus a D. Afonso Henriques. Mas, com a morte do rei, em 1656, a profecia não havia se concretizado. Vieira logo afirma que quem haveria de ressuscitar seria D. João IV. Interpretando as trovas de Bandarra, Vieira afirma, com veemência:

Resumindo tudo a um silogismo fundamental, digo assim: - $O$ Bandarra é verdadeiro profeta; o Bandarra profetizou que El-rei D. João o quarto há-de obrar muitas cousas que ainda não obrou, nem pode obrar senão ressuscitando; logo, El-rei D. João o quarto há-de ressuscitar (VIEIRA, 1951, p. 2).

Ao avaliar as circunstâncias das fortes palavras de Vieira, que obtiveram recepções ambíguas - ele gozava de grande popularidade entre importantes monarcas, figuras da nobreza e do clero, mas teve algumas afirmações contestadas pela Inquisição - Bosi propõe que a aspiração milenarista do padre à ascensão de um monarca absoluto e de um império unificado é consequência de sucessivas guerras, comuns à época, motivadas 
pela rivalidade entre os reis católicos da França, da Espanha, da Áustria e de Portugal - daí a necessidade de unificação.

Sonhos gestados no período de abatimento e sujeição do reino à Coroa de Espanha, "aquela noite eterna de sessenta anos tão compridos" (VIEIRA apud BOSI, 2009), que se seguiu ao desastre de Alcácer-Quibir e ao desaparecimento de D. Sebastião? Possivelmente (BOSI, 2009, p. 40).

Varela (1996) sugere que uma escatologia messiânica, uma história do futuro, como a que pregava Vieira, sempre animou a alma lusitana, mesmo, ou principalmente, nos momentos de maior sofrimento, crise e dilaceramento de seu tecido social. Nesse sentido, propõe que a razão em língua portuguesa é uma razão indefinida nela mesma, eksistente, ou seja, só existe fora de si própria: um heterologos. Citando Fernando Pessoa: "É a busca de quem somos na distância de nós" (PESSOA apud VARELA, 1996, p. 55). Para Varela, o heterologos parece só existir na distância e dá ao português "sentido à sua transcendência metafísica e desassossego existencial. A viagem foi sempre o jeito português de navegar, mais do que de existir, a sua forma peculiar de estar no mundo, desejando o impossível, o infinito, o mar!..." (VARELA, 1996, p. 55). Numa eterna viagem - o epos -, navegando para existir, os portugueses erram naturalmente, errância física e metafísica, porque errar é o seu jeito natural de ser, uma razão nômade. Terra marítima, tem o mar, infinito, "o nada desse todo abissal que é o mar" (VARELA, 1996, p. 58), como único destino possível. Se é na travessia, na viagem, que se tenta atingir a distância infinita, é o epos a coordenada simbólica do heterologos. O epos, portanto, é a procura errante pela própria identidade, mas no outro. O messianismo se insere nesse contexto como "coordenada ôntico-simbólica" do heterologos:

o messianismo escatológico manifesta-se na poiesis em língua portuguesa através de um simbolismo profético e redentor, sendo o sebastianismo a sua forma mais originária, a sua expressão 
antropológica situada. Na poesia filosofante e na filosofia poetizante, portuguesa ou brasileira, os mitologemas sebastianista e quintoimperialista, nas suas variações diacrônicas e metamorfoses, parecem fazer parte de um inconsciente coletivo comum, manifestando, em um nível profundo e latente, a antropologia e teleologia de um pensarsentir em português (VARELA, 1996. p. 270).

No Brasil, como propõe a autora, o mito está arraigado no imaginário popular quase como religião, com expressão própria, surgindo com maior força em momentos de crise ou de perda de identidade, num eterno retorno. Seu principal propagador no Brasil foi Vieira (VARELA, 1996), que esteve na colônia em diferentes ocasiões e regiões (HANSEN, 1999). Hoje, no entanto, tem-se que "o herói não é um príncipe predestinado, não é mesmo um povo. É o Homem" (BRUNO apud VARELA, 1996, p. 168). Não haveria de ser, necessariamente, o rei desaparecido quem retornaria.

Ao longo de toda a filmografia de Glauber, é evidente o recurso às narrativas míticas, e, em Deus e o diabo, o Sebastianismo quinto-imperialista - herança da colonização - é marcante. Com isso, o diretor parece demonstrar a forte influência mítica no imaginário nacional - seu eterno retorno - , pois as ações deverão partir da tomada de consciência e posterior superação. Uma história cíclica e abismal, que faz ressurgir velhos mitos, de tempos em tempos, com novos e desconhecidos rostos. Por outro viés, na épica glauberiana, errância e eterno retorno mítico fazem emergir eras imaginárias lezamianas: diferentes temporalidades convivem num mesmo espaço. Nessa perspectiva, é possível compreender que a trajetória errante de Manuel ao longo de todo o filme, e suas relações com as figuras paternalistas, tenham relações com o Sebastianismo. Mas, se ao longo do filme, o personagem se lançou à errância, ao movimento circular no sertão, ao menos no fim da saga aparece em uma corrida em linha reta. Xavier (1983) propõe que há uma lacuna nos planos finais do filme, entre a corrida de Manuel, em um "voo cego pela Caatinga", e o plano seguinte, com o mar em destaque, no qual o protagonista não mais aparece. Este hiato demonstraria que "a insurreição está sempre no horizonte. Não importa se consciente, passivo 
ou mergulhado na franca alienação, o oprimido traz uma disponibilidade para a revolta, mesmo que subterrânea" (XAVIER, 1983, p. 89). Mesmo na errância emerge a resistência. E, dessa forma, para o autor, todo o filme se caracterizaria por uma preparação à "revolução". Seja na alienação religiosa do beato, seja na entrega à violência, os personagens se mostram resistentes, e suas ações - e o próprio filme - , de tão contraditórias, provocam desestabilização da ordem vigente. É como sugerem dois importantes personagens ao longo da obra: Antônio das Mortes afirma que os mitos - ele e Corisco - precisam ser superados, para que depois, e através deles, uma guerra maior tenha lugar, dessa vez sem a cegueira de deus e do diabo. Já Corisco, logo antes de morrer, grita veementemente: "Mais fortes são os poderes do povo!". E ao longo da corrida na cena final, o cantador desenvolve: "A terra é do homem, não é de Deus nem do Diabo". O filme destrói os clichês maniqueístas da dominação colonial e mítica para sair do círculo errante através da inteligência coletiva, da ação do homem comum. Apropria-se do mito e através dele - propondo sua ruptura e superação - explicita a tensão com a qual foi incorporado na colônia, fazendo emergir o "entrelugar" barroco, pondo em crise as dualidades citadas no início deste artigo. A própria forma diferenciada com a qual o mito foi incorporado às diversas crenças já traz em si a diferença americana.

Deus e o diabo é uma fábula, mas traça um paralelo com o contexto histórico de produção, o início da década de 1960. Se o cinema, inclusive o tido como ficcional, é sempre um fato de linguagem, discurso produzido e controlado por uma fonte produtora (XAVIER, 2008), e se todo discurso histórico é uma ficção do sujeito, e o historicismo sempre recai no plano da linguagem (LEZAMA LIMA, 1988), por meio da ficção Glauber inscreve, entre o eterno retorno mítico e o contexto histórico, uma visão de mundo propriamente americana. Quanto à forma, trata-se de um filme duro e forte, pois, como Glauber argumenta, naquele momento histórico, dado o cenário peculiar das artes e do cinema brasileiro que contaminavam o terreno geral do político - , era preciso realizar "filmes feios e tristes, filmes gritados e desesperados onde nem sempre a razão falou mais 
alto" (ROCHA, 2004, p. 66), em oposição a uma exposição carnavalesca do país. Um miserabilismo daquele Cinema Novo que se opunha às "artes digestivas". Em outras palavras, a forma dura é justificada pelo contexto, mas há, no filme, decisivamente, algo que vai além do simples denuncismo, que não busca mostrar ao público a receita da revolução, mas sim lhe dar visibilidade e subsídios para que possa, ele próprio, tomar consciência de sua própria existência.

\section{Barroco, modernismo, Cinema Novo}

As ações do Cinema Novo, de acordo com Mota (2010), compõem um movimento de retomada e continuidade - uma ponte para as ditas vanguardas modernistas de início do século. Segundo a autora, existem linhas de ideias comuns entre os dois movimentos, com destaque para: forte tendência à produção de manifestos; valorização da língua enquanto materialidade viva da expressão humana; personagens emblemáticos que emergem da geografia e da paisagem - floresta, cidade e sertão - ; ampla pesquisa das manifestações da cultura popular de todo o país; e a complexa apropriação de seus elementos estruturais, num "reconhecimento dos valores estéticos do acervo popular, herdados das tradições indígenas, africanas e ibéricas e seus sincretismos, com acento no aspecto miscigenado e híbrido dessas manifestações" (MOTA, 2010, p. 2).

Para Dias (1972), uma das importantes contribuições do grupo de modernistas para a radical mudança na face cultural do país foi a redescoberta consciente do acervo barroco e sua reavaliação estética, com múltiplos desdobramentos. O que parece ter despertado a atenção desses artistas foi a tensão que identificaram a posteriori nas obras revisitadas, realizadas em um regime artístico retórico-poético fechado: para os modernistas, lá emergia a diferença, mesmo na imitação. Não se tratou de interpretação histórica, mas sim de fazer uso. 
Hansen pondera sobre a importância de considerar, nas análises, a contemporaneidade das obras, pois princípios tratadísticos regulavam as práticas de representação ao longo do século XVII luso-brasileiro:

[...] a doutrina das artes é aristotélico-escolástica, sendo prescrita como um sistema regrado de operações dialético-retóricas de definição, análise e ornamentação das matérias representadas nas obras. É uma técnica - não uma "estética" - que regula os efeitos, funcionando como o saber-fazer de uma instituição anônima e coletivizada de lugares comuns $[\ldots]$ o estilo é prescritivo e funda-se em pressupostos miméticos: a representação emula modelos ou autoridades (HANSEN, 1995, p. 40, grifo do autor).

O autor demonstra que critérios à época contemporâneos devem ser levados em conta ao trabalhar, em termos de interpretação histórica, as representações seiscentistas e setecentistas, uma vez que "arquitetos, escultores, pintores e poetas [...] recorriam a um fundo comum de temas e formas, que achavam em autoridades do que se poderia chamar uma poética do ut pictura poesis" (HANSEN, 1995, p. 42).

Em $A$ sátira e o engenho, obra na qual discorre sobre a poesia de Gregório de Matos, Hansen (2004) demonstra que conceitos modernos de autoria individualizada, originalidade, novidade estética e plágio não eram conhecidos pelos artistas de então, e sua utilização nas análises de tais obras é fruto de releituras e reinterpretações posteriores que buscaram unificar as produções. Impensáveis à época, não foram, portanto, sua causa ou origem e revelam-se anacrônicos quando aplicados em uma análise de estilo. Gregório obedecia a regras discursivas de seu tempo. No entanto, Hansen considera que apropriações concretistas das obras, ao isolar os procedimentos técnicos do poeta e autonomizá-los apologeticamente, se validam heuristicamente, assim como a "deglutição oswaldiana" dos mesmos procedimentos via interpretações da antropofagia cultural e do Tropicalismo, que teriam visto em Gregório de Matos um precursor. O poeta pertenceu a um modelo mimético no qual a imitação era a regra; logo, criatividade e tensionamento eram propostas 
impensáveis. Mas os modernistas, em um tempo outro, criando bases para um novo projeto artístico, a partir de seus próprios conceitos, se interessaram por uma mestiçagem que viram no léxico, na linguagem de Gregório a posteriori o que não quer dizer que houve intenção do autor à época - , o que passaria a caracterizar uma tensão pela apropriação, na colônia, do modelo artístico trazido pelo colonizador europeu. O objetivo maior dos modernistas, portanto, era fazer uso dessa mestiçagem sem nenhuma pretensão de interpretação histórica. A operação é válida como analogia na "descrição do experimental da neovanguarda com agudeza engenhosa que aproxima e funde conceitos distantes" (HANSEN, 2004, p. 33).

Uma passagem por Rancière (2005) se fará útil. O autor propõe que um regime estético das artes, o qual opõe ao regime mimético - este último pode ser equiparado ao que Hansen nomeia doutrina aristotélico-escolástica das artes -, está marcado pelas "redescobertas" - de Homero como poeta, apesar de si mesmo, por Vico; de Rembrandt, pelos realistas do século XIX; e aqui se pode inserir também a redescoberta do barroco pelos modernistas. Não se trata, portanto, de uma oposição entre antigo e moderno, mas, sim, de dois regimes de historicidade: "no regime estético da arte, o futuro da arte, sua distância do presente da não-arte, não cessa de colocar em cena o passado" (RANCIÈRE, 2005 p. 35). Um novo regime da relação com o antigo; uma copresença de temporalidades heterogêneas.

Fica claro, portanto, que os modernistas não se preocuparam com anacronias, pois fizeram uma releitura sem pretensões de interpretação histórica. Queriam simplesmente fazer uso do que viam no passado em um novo projeto artístico. Em termos de aproximação de ideias, fato é que o arejamento intelectual causado na intelectualidade brasileira pelos modernistas - além da renovação estética que propuseram na literatura, nas artes plásticas e na música - parece ter sido decisivo para o surgimento, décadas mais tarde, do Cinema Novo - impregnado, portanto, do novo olhar sobre o barroco adquirido por esses modernistas. Mas não se deve ignorar que existiram outras determinantes históricas e sociais que também deram liga ao movimento do Cinema Novo. 


\section{Referências}

BOSI, A. "Antônio Vieira profeta e missionário: um estudo sobre a pseudomorfose e a contradição". In: DUARTE, L. P. (Org.). Padre Antônio Vieira: 400 anos depois. Belo Horizonte: PUC Minas, 2009.

Dialética da colonização. São Paulo: Companhia das Letras, 1992.

BRAGANÇA, M. de. "Alteridade, conflito e resistência no Barroco de Paul Leduc". In: AMANCIO, T. et al (Orgs.). Estudos de Cinema Socine: IX. São Paulo: Annablume, 2008.

DIAS, F. C. "A redescoberta do barroco pelo movimento modernista". Barroco, Belo Horizonte, n. 4, 1972.

HANSEN, J. A. A sátira e o engenho: Gregório de Matos e a Bahia do século XVII. 2. ed. rev. São Paulo: Ateliê, 2004.

. "Padre Antônio Vieira: sermões". In: MOTA, L. D. (Org.). Introdução ao Brasil: um banquete no trópico. São Paulo: Senac, 1999.

- "Teatro da memória: monumento barroco e retórica". Revista do IFAC, Ouro Preto, n. 2, p. 40-54, dez. 1995.

LEZAMA LIMA, J. A expressão americana. São Paulo: Brasiliense, 1988.

MOTA, R. "Roteiros do cinema e do modernismo brasileiro". Contemporanea, Salvador, n. 2, v. 8, dez. 2010.

NAGIB, L. A utopia no cinema brasileiro: matrizes, nostalgia, distopias. São Paulo: Cosac Naify, 2006.

RANCIÈRE, J. A partilha do sensível: estética e política. São Paulo: editora 34, 2005.

ROCHA, G. Revolução do Cinema Novo. São Paulo: Cosac Naify, 2004.

VARELA, M. H. O heterologos em língua portuguesa: elementos para uma antropologia filosófica situada. Rio de Janeiro: Espaço e Tempo, 1996. 
VIEIRA, A.; ALVES, G. Sermões: volume 1: tomos 1, 2 e 3. Porto: Lello \& Irmão, 1959. VIEIRA, A.; SÉRGIO, A.; CIDADE, H. Obras escolhidas: volume 6: obras várias (IV). Vieira perante a inquisição. Lisboa: Sá da Costa, 1951.

XAVIER, I. O discurso cinematográfico: a opacidade e a transparência. São Paulo: Paz e Terra, 2008.

Sertão mar: Glauber Rocha e a estética da fome. São Paulo: Brasiliense, 1983. 